\title{
Two-stage electro-discharge machining fabricating superhard cutting tools
}

\author{
A.G. Mamalis ${ }^{\text {a,* }}$, A.I. Grabchenko ${ }^{\text {b }}$, M.G. Magazeev ${ }^{\text {b }}$, N.V. Krukova ${ }^{\text {, }}$, \\ J. Prohàszkác ${ }^{\mathrm{c}}$ N.M. Vaxevanidis ${ }^{\mathrm{a}}$ \\ a Manufacturing Technology Division, Department of Mechanical Engineering, National Technical University of Athens, Athens 10682, Greece \\ b Department of Cutting Materials and Cutting Tools, National Technical University "Kharkov Polytechnical Institute”, Kharkov, Ukraine \\ ${ }^{\mathrm{c}}$ Hungarian Academy of Sciences, Budapest, Hungary
}

Received 12 October 2001; accepted 3 October 2003

\begin{abstract}
A novel technique for fabricating efficiently precision cutting tools made from polycrystalline superhard materials is reported in the present paper. For this purpose, a two-stage electro-discharge machining (EDM) was applied on diamond polycrystallines, by employing first wire-electrode EDM for rough cutting and subsequently rotational disc-electrode EDM for finishing operations. Experimental results obtained clearly indicate the applicability of the proposed two-stage technique for fabricating precision cutting tools that can be used for the production of machined components made from glass and plastics, ceramics, composite materials and non-ferrous metals, at an industrial scale.
\end{abstract}

(C) 2003 Elsevier B.V. All rights reserved.

Keywords: Two-stage electro-discharge machining; Diamond polycrystalline superhard materials; Rotational disc-electrodes; Wire-EDM; Cutting tool

\section{Introduction}

Precision machining technology has been developed over recent years for the fabrication of quality-assured and costeffective precision components for various industrial sectors such as optics, microelectronics, automobile and aerospace applications. Several machining techniques are available for this purpose; among them diamond turning, diamond grinding and laser machining are the most extensively applied [1].

Increased application of precision machining technology results in an increasing demand for precision cutting tools made of polycrystalline superhard materials (PSHM). However, the manufacture of such tools by diamond grinding gives rise to difficulties, associated with the high cost of diamond wheels, large consumption of diamonds and laborious processing. Moreover, diamond grinding is characterized by significant mechanical and thermal impacts on the workpiece, resulting in the formation of splits and flaws on the cutting edge, and, therefore, in a great number of defective and rejected tools. Worth mentioning also, that the shape of the "as received" synthesized PSHM does not

\footnotetext{
* Corresponding author. Tel.: +30-1-772-3688; fax: +30-1-772-3689. E-mail address: mamalis@central.ntua.gr (A.G. Mamalis).
}

coincide with the required shape of the tool's cutting edge; therefore, waste and losses of such an expensive material during grinding are unavoidable.

On the other hand, whereas the efficiency of "traditional" cutting processes is limited by the mechanical properties of the processed material and the complexity of the workpiece geometry, electro-discharge machining (EDM), being a thermal erosion process, is not subjected to such restraints. EDM, nowadays, is extensively and successfully applied for machining difficult-to-work materials such as HSLA steels, ceramics, carbides and composites [2-6]. In fact, EDM is the best-and sometimes-the only candidate, when all mechanical processes fail, providing that the material under consideration is sufficiently electrically conductive. Two techniques are currently available, die-sinking and wire cutting (W-EDM), depending upon the certain application [5].

Apart from certain ceramics, such as boron carbide and titanium boride displaying good electrical conductivity, engineering ceramics are considered to be non-conductors by virtue of their polar bonding nature. However, these non-conductors can be rendered conductive either by doping with conductive elements or by incorporating impurity atoms [3]. Diamond is, by nature, dielectric material, however, since for the effective synthesis of most diamond 
PSHM types, the presence of a certain amount of electrically conductive elements such as metal bond, metal-catalysts, their carbides and nitrides and/or graphite is required; conductive, ED-machinable grades can be obtained. Processing of such PSHM grades for fabricating precision cutting tools by applying successfully EDM has been already reported $[7,8]$. Metallurgical studies and simulation verified that a "threshold" $4 \%$ amount of conductive elements is needed for diamond PSHMs to become erodable [9].

In the present paper we report on a novel technique for fabricating efficiently precision cutting tools made from polycrystalline superhard materials. For this purpose, a two-stage electro-discharge machining (EDM) of diamond PSHMs was applied, by employing first wire-electrode EDM for rough cutting and subsequently rotational disc-electrode EDM for finishing operations. The present work summarizes the extensive research reported in [10] taking also into account previous researches concerning various aspects of surface integrity of EDMed surfaces as well as an investigation into machinability in W-EDM (see Refs. [2,5,11]). Experimental results obtained clearly indicate the applicability of the proposed two-stage technique for fabricating precision cutting tools used for production of machined components made from advanced brittle materials such as, glass and plastics, ceramics, composites and non-ferrous alloys.

\section{Wire-EDM of diamond PSHMs}

\subsection{Materials and processing}

Experiments were performed on a standard wire electrodischarge machine tool (model 4732F3M) and commercially available brass wire (brand name: DKRPM L63) was employed. The W-EDM processing parameters were: wire-electrode diameter, $d_{\mathrm{we}}=0.15$ and $0.30 \mathrm{~mm}$; wireelectrode tension, $F_{\mathrm{ew}}=8$ and $10 \mathrm{~N}$; velocity of wireelectrode travel, $V_{\text {we }}=25 \mathrm{~mm} / \mathrm{s}$; pulse duration, $t_{\mathrm{e}}=3 \mu \mathrm{s}$ and dielectric fluid water.

For W-EDM of ceramics the principal limit factor appear to be the electrical conductivity of the material. Once a ceramic has become erodable (e.g. by doping) the processes can be implemented and optimized; overall performance being depended upon operational parameters and the equipment employed [3,5]. A market search for commercially available diamond PSHMs revealed a number of candidate materials; they are listed in Table 1.

Two commercially available ED-machinable grades (Ukrainian brand names: ATP and SKM-R) were used as workpiece materials. These grades can be supplied in the form of discs with diameter more than $8 \mathrm{~mm}$ being therefore suitable for fabricating edged cutting tools. The main physical and mechanical properties as well as the dimensions of the test materials, together with the same parameters of grade "Syndite" used in similar research [7], are presented in Table 2.

SKM-R is a synthetic diamond PSHM, obtained by sintering diamond powder with an average grain size of $8-10 \mu \mathrm{m}$ together with nickel-silicon powder as bonding phase. ATP is a two-layered diamond plate on hard alloy substrate, obtained by sintering a mixture of diamond powders with average grain $40-60 \mu \mathrm{m}$ with cobalt as bonding phase.

\subsection{Experimental results}

From the experimental work performed and taking also into account observations from similar previous researches $[3,4,6,10,12]$ it is evident that material removal during W-EDM of diamond PSHM involves a superposition of

Table 1

Commercially available diamond PSHMs and ED-machinable grades

\begin{tabular}{|c|c|c|c|c|}
\hline Method of fabrication & Additives (dopes) & $\begin{array}{l}\text { Percentage of } \\
\text { electro-conducting } \\
\text { compounds }\end{array}$ & $\begin{array}{l}\text { Application } \\
\text { of EDM }\end{array}$ & Brand \\
\hline Synthesis from graphite & Metal-catalysts & $4-20$ & Possible & ASB, ASPK, ASPB, ASF (IPhVD, Russia) \\
\hline \multirow[t]{3}{*}{$\begin{array}{l}\text { Sintering of diamond } \\
\text { powders }\end{array}$} & - & $\begin{array}{l}\text { Less than } 1 \text { (products } \\
\text { of graphitization) }\end{array}$ & Impossible & $\begin{array}{l}\text { Carbonite (ISM, Ukraine), Megadiamond } \\
\text { (Megadiamond Corp., USA) }\end{array}$ \\
\hline & $\begin{array}{l}\text { Active dopes (carbides } \\
\text { of metals, etc.) }\end{array}$ & $2-6$ & $\begin{array}{l}\text { Possible in } \\
\text { some cases }\end{array}$ & $\begin{array}{l}\text { SV, SVAB (VNIITS, Russia), ALV, Dismit } \\
\text { (ISM, Ukraine), Syndax, Geoset, Formset } \\
\text { (General Electric, USA) }\end{array}$ \\
\hline & $\begin{array}{l}\text { Bonding materials } \\
(\mathrm{Co}, \mathrm{Ni}, \mathrm{Fe}, \mathrm{Cr}, \mathrm{Si} \text {, etc. })\end{array}$ & $6-30$ & Possible & $\begin{array}{l}\text { SKM-R (PAZ, Ukraine), ATP, BPA (ISM, } \\
\text { Ukraine), DAP, Diamet (VNIIAlmaz, } \\
\text { Russia), Syndite (De Beers Industrial } \\
\text { Diamond Division, USA) Compax, } \\
\text { Stratapax (General Electric, USA), Sumidia } \\
\text { (Sumitomo Electric, Japan), Sunpax } \\
\text { (Toshiba Tungaloy, Japan), Seropax } \\
\text { (Diamant Bort, Belgium), Polybloc (Winter, } \\
\text { Germany), Novotyps (Novatechnik, } \\
\text { Germany), Diatypt (Precidia, France) }\end{array}$ \\
\hline
\end{tabular}


Table 2

Physical and mechanical properties of ED-machinable diamond PSHM grades ${ }^{\mathrm{a}}$

\begin{tabular}{|c|c|c|c|c|c|c|c|c|c|c|}
\hline \multirow[t]{2}{*}{ Brand } & \multirow{2}{*}{$\begin{array}{l}\text { Vickers, } \\
\text { hardness } \\
(\mathrm{GPa})\end{array}$} & \multirow{2}{*}{$\begin{array}{l}\text { Compressive } \\
\text { strength } \\
(\mathrm{GPa})\end{array}$} & \multirow{2}{*}{$\begin{array}{l}\text { Modulus of } \\
\text { elasticity } \\
(\mathrm{GPa})\end{array}$} & \multirow{2}{*}{$\begin{array}{l}\text { Thermal } \\
\text { resistance } \\
\text { on air }(\mathrm{K})\end{array}$} & \multirow{2}{*}{$\begin{array}{l}\text { Thermal } \\
\text { conductivity } \\
(\mathrm{W} / \mathrm{m} \mathrm{K})\end{array}$} & \multirow{2}{*}{$\begin{array}{l}\text { Size of } \\
\text { diamond } \\
\text { grains }(\mu \mathrm{m})\end{array}$} & \multirow[t]{2}{*}{$\begin{array}{l}\text { Bonding } \\
\text { phase }\end{array}$} & \multicolumn{3}{|c|}{$\begin{array}{l}\text { Sizes of diamond } \\
\text { polycrystalline }(\mathrm{mm})\end{array}$} \\
\hline & & & & & & & & $d$ & $h$ & $h^{*}$ \\
\hline SKM-R & $80-90$ & 5.0 & 850 & 970 & $150-250$ & $8-10$ & Ni-Si $(8 \%)$ & 8 & 4.5 & - \\
\hline ATP & $72-80$ & - & 882 & 970 & $156-385$ & up to $40-60$ & Co $(8.5 \%)$ & 13.5 & 3.5 & 0.7 \\
\hline Syndite & $50-60$ & 7.6 & $850-925$ & 970 & $420-560$ & $2,10,25$ & Co $(20 \%)$ & 30 & 3.2 & 0.5 \\
\hline
\end{tabular}

a $d$ : diameter, $h$ : height, $h^{*}$ : height of diamond layer.

several processes, i.e.:

- splitting and falling-out of some diamond grains from the matrix of the material, due to the evaporation and melting of the surrounding metal bond and the electro-conductive dopes (additives);

- evaporation and thermal destruction of grains, in contact with the high-temperature plasma channel of the electrical discharge;

- brittle thermospalling of grains as a result of thermal impact, i.e. due to their strong heating-up during the passage of an electrical pulse and the subsequent fast cooling by the dielectric fluid.

It should be noted that, high hydrodynamic impact loads developed during the electrical discharge in the dielectric, intensify the first and third mechanisms. Worth mentioning also that the relative influence of each mechanism on the overall removal rate depends upon the process parameters and the thermal as well as the physical properties of the material. In rough cutting, when the pulse energy is large, material removal takes place mainly due to falling-out of the whole grains. Under finishing conditions, evaporation and graphitization of diamond crystals dominate.

The high efficiency of the W-EDM of diamond PSHMs has been observed by previous researches $[6,7,10]$ and the present experimental results agreed well with them. On the other hand, some additional features due to the specific combination of material removal mechanisms prevailing were also identified.

- The minimal value of pulse energy, $W_{\mathrm{e} \text { min }}$, below which EDM of diamond PSHMs cannot be performed has been examined and was found that this "threshold" is for SKM-R grade, with grain size is $8-10 \mu \mathrm{m}, W_{\mathrm{e} \text { min }}=$ $0.009 \mathrm{~mJ}$ and for ATP grade, with grain size up to $60 \mu \mathrm{m}$, $W_{\text {e min }}=0.075 \mathrm{~mJ}$. Note that, for the fine-grained grades this minimum value of pulse energy is lower than for the coarse-grained ones.

- With pulse energies up to $W_{\mathrm{e}}=0.02-0.04 \mathrm{~mJ}$, material removal, mainly, occurs due to the evaporation and thermosplitting of the polycrystalline grains. These energies constitute a range of finishing conditions for W-EDM.

- With increasing pulse energy, i.e. for roughing W-EDM, material removal mechanism is dominated by the falling-out of the whole grains, due to burning-out of the surrounding bonding material.
Based on an optimization of the processing parameters (electrical pulses, composition of dielectric, diameter of the wire-electrode), the highest material-removal rate achieved during W-EDM of diamond PSHMs was $10.5 \mathrm{~mm}^{3} / \mathrm{min}$ for ATP grade and $13 \mathrm{~mm}^{3} / \mathrm{min}$ for SKM-R grade. It should be noted that, the processing of coarse-grained PSHM grade occurs more slowly than fine-grained ones, since the coarse grains are more strongly connected to the sub-surface material structure. For comparison purposes, it should be mentioned that the material-removal rate for grade SYNDITE-002 (grain size is $2 \mu \mathrm{m}$ ) was $21 \mathrm{~mm}^{3} / \mathrm{min}$ and for SYNDITE-010 (grain size $10 \mu \mathrm{m}$ ) $15 \mathrm{~mm}^{3} / \mathrm{min}$, using a Robofil-2000 machine tool [7]. The variation of material removal-rate with pulse energies applied is illustrated in Fig. 1.

A characteristic feature of W-EDM of two-layered plates (ATP grade) is the formation of a cavity on the processed surface, at the interface of the hard-alloy substrate and the PSHM layer, attributed to the increased content of the bonding phase (cobalt) in this transition zone. Mathematical modeling indicated, that the depth of the zone of thermal defects cannot exceed $4 / 3$ times the depth of the cavity, since at this value of depth the temperature calculated is always lower than the temperature of phase-transformation isothermal for diamond and cobalt [8]. With decreasing pulse energy, the depth of the cavity decreases, and, for $W_{\mathrm{e}}<0.4 \mathrm{~mJ}$, becomes practically identical to the microroughness of a profile (see Fig. 2). Thus, it can be supposed that after "finishing",

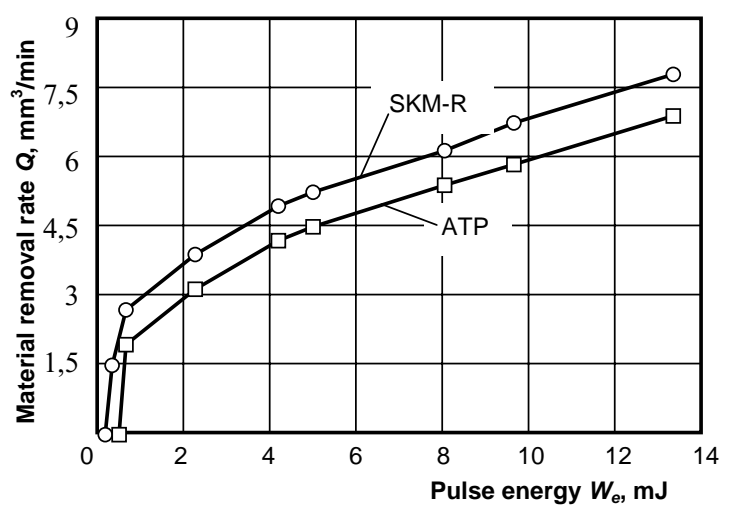

Fig. 1. Variation of material-removal rate with pulse energy of W-EDM of diamond PSHMs $\left(d_{\mathrm{we}}=0.3 \mathrm{~mm} ; F_{\mathrm{we}}=10 \mathrm{~N}\right.$; dielectric fluid- $\mathrm{H}_{2} \mathrm{O}$; $\left.t_{\mathrm{e}}=3 \mu \mathrm{s}\right)$ 


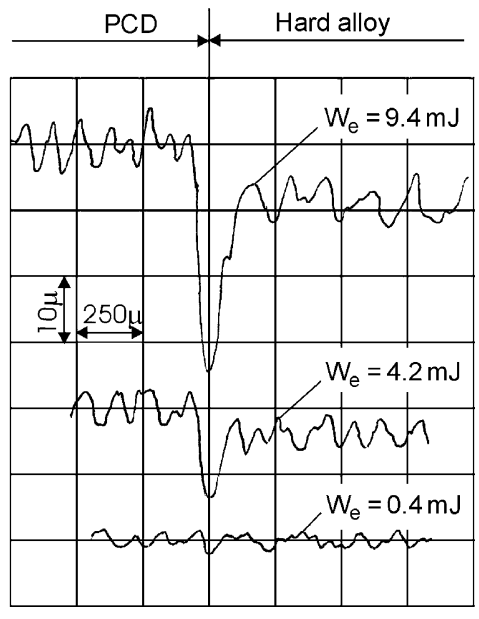

Fig. 2. Profilographs of W-EDMed surfaces of two-layered ATP grade $\left(d_{\mathrm{we}}=0.3 \mathrm{~mm} ; F_{\mathrm{we}}=10 \mathrm{~N}\right.$; dielectric fluid- $\left.\mathrm{H}_{2} \mathrm{O} ; t_{\mathrm{e}}=3 \mu \mathrm{s}\right)$.

the depth of the zone of thermal microstructural changes does not exceed $4 / 3$ of $R_{\max }$, i.e. 5-12 $\mu \mathrm{m}$. Note, also, that scanning electron microscopy, performed with a magnification up to $2000 \times$ revealed that, even under the most roughing conditions $\left(W_{\mathrm{e}}=13.5 \mathrm{~mJ}\right)$, cracks were not formed.

The variation of average surface roughness, $R_{\mathrm{a}}$, with pulse energy for the two W-EDMed grades is presented in Fig. 3. From these plots it is evident that $R_{\mathrm{a}}$ increases, almost linearly, with increasing pulse energy. However, for low pulse energies, close to the minimal threshold value, $W_{\mathrm{e} \min }$, instability of the process caused significant vibrations of the electrode-wire, leading therefore to a sharp increase of surface roughness for very low energies (see Fig. 3). In general, surface roughness values measured during W-EDM of diamond PSHMs are rather large $(0.95-1.8 \mu \mathrm{m})$ and does not meet the surface quality requirements for PSHM cutting tools. On the contrary, it is evident that W-EDM can be implemented successfully for rough cutting of tool profiles, reducing the overall fabrication time and saving expensive material (diamond PSHM grades), as compared with dia-

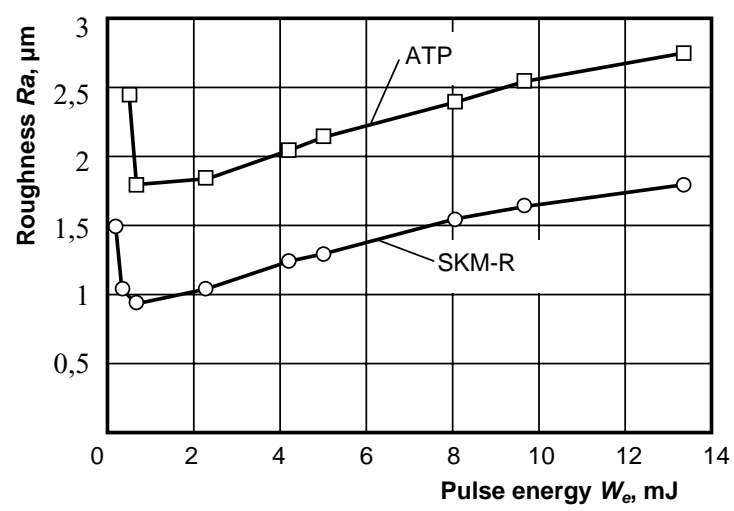

Fig. 3. Variation of surface roughness, $R_{\mathrm{a}}$, with pulse energy during W-EDM of diamond PSHMs $\left(d_{\mathrm{we}}=0.15 \mathrm{~mm} ; F_{\mathrm{we}}=8 \mathrm{~N}\right.$; dielectric fluid- $\left.\mathrm{H}_{2} \mathrm{O} ; t_{\mathrm{e}}=3 \mu \mathrm{s}\right)$. mond grinding usual employed for such works (see for the latter Ref. [13]).

The rather low surface quality imparted from W-EDM is attributed to the low rigidity of the electrode-wire, leading to local vibrations, which are copied on the resulted surface. Therefore, replacement of the flexible wire electrode-tool by a rotating disc, in the rotational EDM configuration [6], was applied in order to improve the surface integrity of the machined component at the final finishing stage.

\section{Rotational disc-electrode EDM of diamond PSHMs}

\subsection{Machine tool concept}

The rotational EDM configuration (R-EDM) is schematically presented in Fig. 4. The special fixture of the spindle unit on hydrodynamically free spherical plain bearings was mounted on the table of the machine tool. Rotation of the fixture is generated by a dc electrical motor with adjustable revolution speed. By using plain bearings the high precision requirements for the radial and the lateral movement of the disk electrode-tool, are fulfilled since the inter-electrode gap is in the order of a few microns.

For the finishing operations, a disc-electrode of graphite (brand name: MPG-6) with $200 \mathrm{~mm}$ diameter and $20 \mathrm{~mm}$ thickness was used as tool. The speed of the disc-electrode was selected $v_{\mathrm{de}}=5 \mathrm{~m} / \mathrm{s}$ and the pulse duration, $t_{\mathrm{e}}=3 \mu \mathrm{s}$. The dielectric fluids used were water and hydrocarbon fluid (brand name: DT).

\subsection{Experimental observations}

The main features observed during R-EDM are, in general, similar to the ones identified for W-EDM. The material-removal rate of coarse-grained PSHM (ATP grade) is lower than that of fine-grained one (SKM-R grade), and a cavity was also formed on the processed surface of two-layered diamond plates (ATP grade), at the interface of the hard-alloy substrate and the PSHM layer.

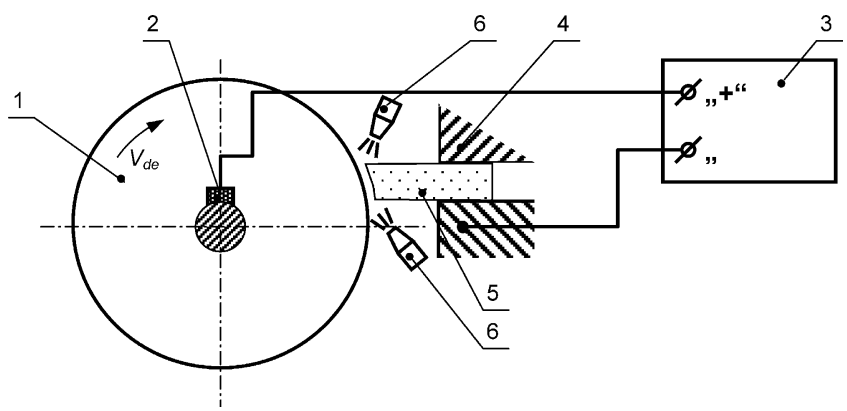

Fig. 4. A schematic diagram of the rotational disc-electrode EDM (R-EDM). (1) Disk electrode-tool; (2) current-collecting device; (3) generator of pulses; (4) fixture; (5) workpiece; (6) nozzles for feeding the dielectric fluid. 


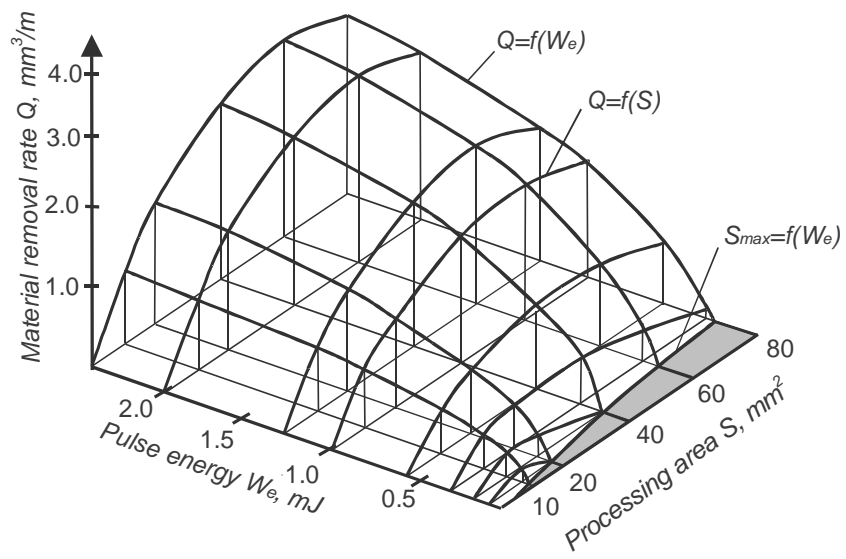

Fig. 5. Variation of material-removal rate, $Q$ with the processing area, $S$ and pulse energy, $W_{\mathrm{e}}$ for R-EDM of ATP grade $\left(V_{\mathrm{de}}=5 \mathrm{~m} / \mathrm{s}\right.$; dielectric fluid- $\left.\mathrm{H}_{2} \mathrm{O} ; t_{\mathrm{e}}=3 \mu \mathrm{s}\right)$.

A 3D-diagram indicating the dependence of rotational EDM material-removal rate, $Q$ on the processing area, $S$ and the pulse energy, $W_{\mathrm{e}}$ for diamond ATP grade is presented in Fig. 5. The curves $Q=f\left(W_{\mathrm{e}}\right)$ (in longitudinal section), $Q=f(S)$ (in cross-section), and also the one representing the dependence with pulse energy, i.e $S_{\max }=f\left(W_{\mathrm{e}}\right)$ (shaded area on the $W_{\mathrm{e}}-S$ plane), are typical for rotational EDM of PSHM materials [10].

The "threshold" pulse energy, $W_{\mathrm{e} \text { min }}$, at which spark erosion of diamond PSHMs can be performed was also identified for R-EDM. However, in this case, this value is directly depended on the machined area, $S$. At an appropriate area reduction, the rotational EDM starts at pulse energy of only, $W_{\mathrm{e}}=0.008 \mathrm{~mJ}$, which is the minimal, permitted value according to the specifications of the machine-tool employed. At this energy level the detailed finishing of flank as narrow smooth strip along the cutting edge can be achieved accurately.

For low pulse energies a maximal critical area, $S_{\max }$, was identified; above this value spark erosion is impossible due to the reduced intensity of the electrical field in the inter-electrode gap. Worth mentioning also, that by increasing the size of polycrystalline grains, the maximum area of processing, $S_{\max }$, is decreasing.

The variation of average surface roughness, $R_{\mathrm{a}}$, with pulse energy, for the two R-EDMed grades is presented in Fig. 6. From these plots is evident that $R_{\mathrm{a}}$ increases, almost exponentially, with increasing pulse energy. The abrupt variation of $R_{\mathrm{a}}$ at low-energy level observed during roughing $\mathrm{W}$-EDM (see Fig. 3), was not evident here, with variation being strictly monotonous (see Fig. 6). Moreover, for the same energy level, $R_{\mathrm{a}}$ values measured for coarse-grained PSHM (ATP grade) are systematically higher than that of fine-grained one (SKM-R grade); a trend exactly opposite to the one observed during roughing W-EDM; compare Figs. 3-6. Minimum $R_{\mathrm{a}}$ values measured, representing best surface finish achievable, was $R_{\mathrm{a}}=0.12 \mu \mathrm{m}$, for SKM-R grade and $R_{\mathrm{a}}=0.20 \mu \mathrm{m}$ for ATP grade, respectively.

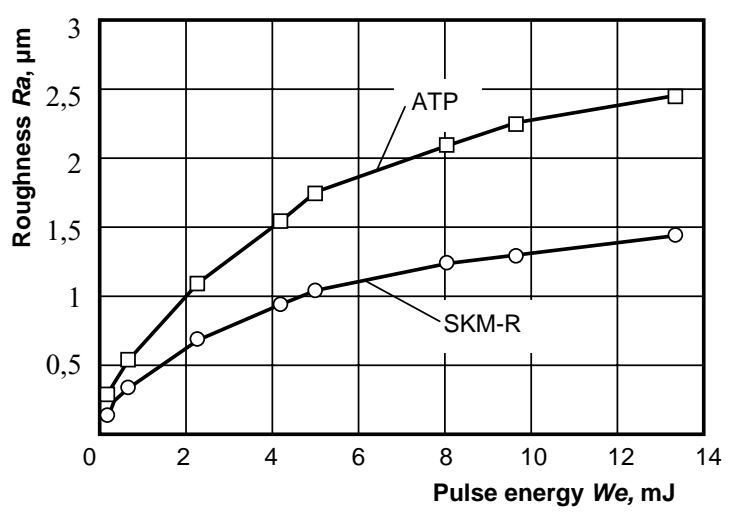

Fig. 6. Variation of surface roughness, $R_{\mathrm{a}}$ with pulse energy during R-EDM of diamond PSHMs $\left(S=8 \mathrm{~mm}^{2} ; V_{\mathrm{de}}=5 \mathrm{~m} / \mathrm{s}\right.$; dielectric fluid-DT; $\left.t_{\mathrm{e}}=1.5 \mu \mathrm{s}\right)$.

\section{Discussion of R-EDM results}

\subsection{Surface finish}

The optimum results were obtained using a graphite discelectrode and hydrocarbon as dielectric fluid. When hydrocarbon is used, pyrolysis of dielectric takes place; therefore a graphite film (containing carbon from dielectric decomposition) is deposited on the machined surface, covering the most protruding grains of the material and thus enhancing the discharges between workpiece and the electrode. In this case a surface with a characteristic "microrelief", smoother than that of R-EDMed with water as dielectric fluid is obtained. The minimal values of microroughness measured are comparable to the ones measured after diamond grinding, and, in most cases, meet the specifications for PSHM cutting tools.

\subsection{Tool cutting edge integrity}

Metallographic examination performed for the comparison of the quality of the cutting edges obtained by diamond grinding, W-EDM and R-EDM reveals that best cutting edge for diamond PSHM grades is obtained by applying R-EDM (see Fig. 7). Grinding of these materials by using standard diamond wheels resulted in the formation of splits and flaws on the cutting edge, with length up to $20 \mu \mathrm{m}$ (see Fig. 7(a)), due to high grinding forces exerted (see also Ref. [13]). Similarly W-EDM resulted in the formation of flaws, with dimensions comparable to the grain sizes of the given PSHM (see Fig. 7(b)). It is clear from the micrographs of Fig. 7(b) that the dimensions of flaws for SKM-R grade are significantly smaller, than those for ATP grade possessing more coarse grains. On the contrary, in R-EDM splits were not identified due to absence of significant mechanical forces and low-impact impact prevailing during processing (see Fig. 7(c)). From this figure is evident that the best edge is formed when processing fine-grained diamond polycrystals (SKM-R) with R-EDM. It is concluded therefore that 


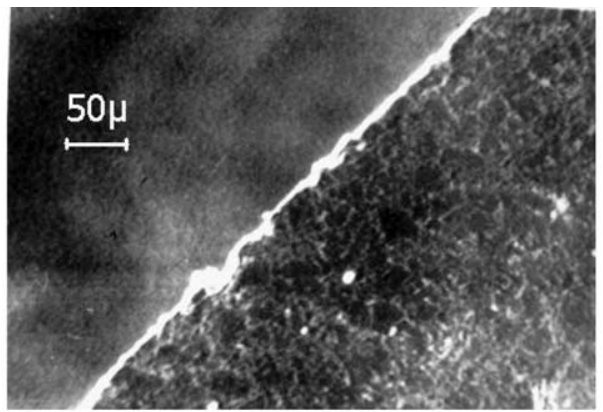

Material: ATP

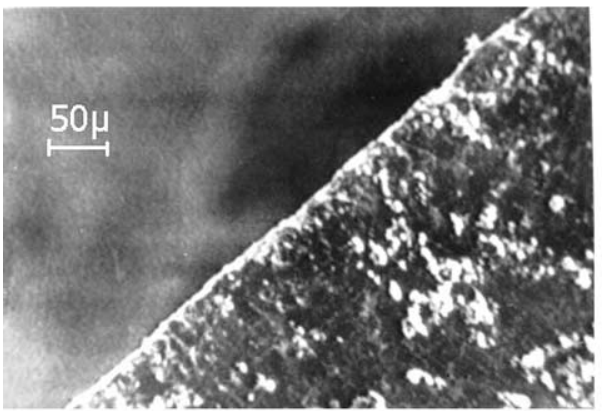

Material: ATP

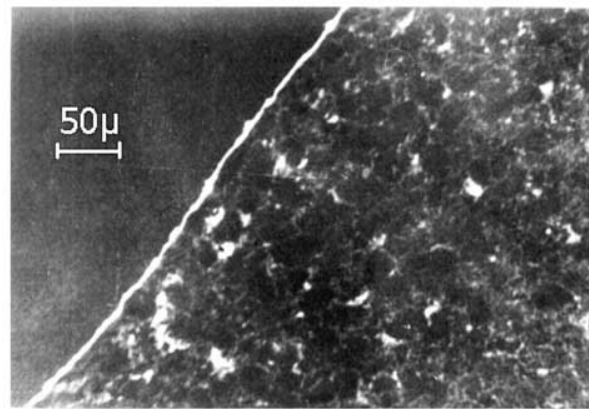

Material: ATP

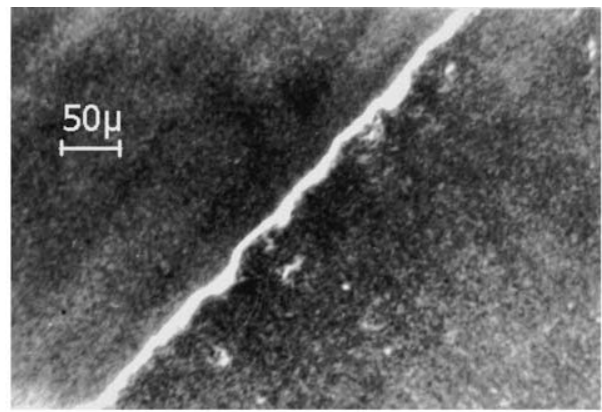

Material: SKM-R

(a)

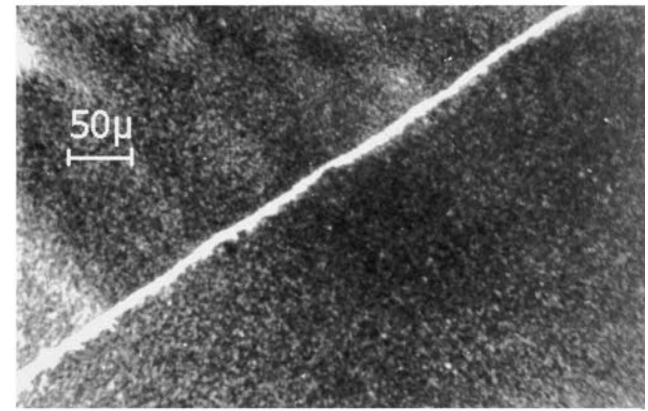

Material: SKM-R

(b)

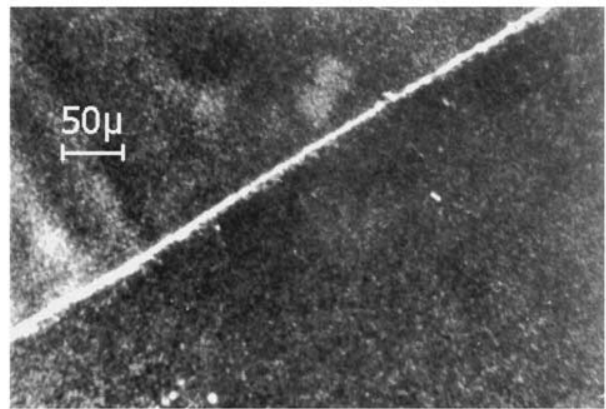

Material: SKM-R

(c)

Fig. 7. Microstructure of the cutting edge of diamond PSHMs after (a) grinding with a diamond wheel, (b) wire-electrode EDM and (c) rotational disc-electrode EDM.

SKM-R grade is the optimum selection for the fabrication of edged tools for finishing operations. Note also that in the case of R-EDM, the dimensional tolerance of cutting tool profile achieved does not exceed $5 \mu \mathrm{m}$, which is acceptable for tools for general mechanical engineering purposes.

From the above-mentioned observations, a two-stage technological scheme for the manufacture of precision edged tools from diamond PSHM is proposed. Initially, cutting of a PSHM "preform" or plate, to workpieces of the given form is performed on a W-EDM machine tool. Subsequently, rotational electro-discharge machining of the flank of the cutting tool is carried out with the help of a disc-electrode, after fixing the workpieces on the tool cage. Finishing of the flat face of the tool by fine-grained diamond wheels with organic bonds is recommended, since in this case, the best surface quality $\left(R_{\mathrm{a}}=0.04-0.08 \mu \mathrm{m}\right)$ is obtained. From workshop experience, it can be stated that the quality of the components, processed by PSHM edged tools, mainly depends on the quality of the tool face, where complex processes of plastic deformation of layer being cut and formation of "slowed down" layer or build-up take place, whilst the influence of flank on surface finish is less profound [9].

\subsection{Tool life}

In order to examine the efficiency of cutting tools manufactured according to the proposed two-stage technological scheme, tool life tests were carried out. Tool life testing 


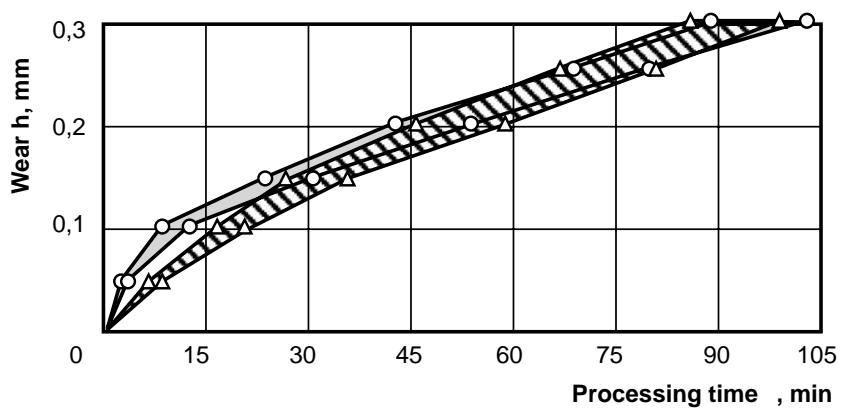

Fig. 8. Variation of flank wear of cutters from SKM-R grade with machining time $(S=0.15 \mathrm{~mm} / \mathrm{rev}, t=0.5 \mathrm{~mm}, V=400 \mathrm{~m} / \mathrm{min})$. $\hat{\phi}^{\Delta}$ grinding;

-Scattered values of wear of cutters sharpened by diamond $\mathrm{P} \rightarrow 0$

- scattered values $f$ wear of cutters sharpened with the help of rotational EDM.

was performed in longitudinal turning of fiberglass composite material (brand name: KACT-B), whilst cutters from SKM-R grade were sharpened $\left(\alpha=10^{\circ}, \gamma=0^{\circ}, \varphi=\right.$ $45^{\circ}, \varphi_{1}=15^{\circ}$ ), by the proposed two-stage technique and conventional diamond grinding. The turning parameters were: cutting speed, $V=400 \mathrm{~m} / \mathrm{min}$; feed rate, $S=0.15 \mathrm{~mm} / \mathrm{rev}$ and depth of cut, $t=0.5 \mathrm{~mm}$. Typical experimental results obtained are presented in Fig. 8. From the graphs, it is indicated that in the early processing stages the wear of the cutters manufactured by the new two-stage technique is higher than that of cutters sharpened by diamond grinding. However, with increasing machining time their efficiencies almost coincides and they both achieve a critical wear for, approximately, the same time. The measured surface roughness for both types of cutters was, $R_{\mathrm{a}}=4.2-4.6 \mu \mathrm{m}$. These relatively high values of roughness are attributed to the fibrous structure of the fiberglass composite material.

When turning aluminum alloy A125 (with turning parameters $V=200 \mathrm{~m} / \mathrm{min}, S=0.05 \mathrm{~mm} / \mathrm{rev}, t=0.3 \mathrm{~mm}$ ), the diamond PSHM cutters manufactured by the proposed two-stage technique resulted in a relatively better quality of the turned surface $\left(R_{\mathrm{a}}=0.9-1.15 \mu \mathrm{m}\right)$, than cutters sharpened by a diamond wheel $\left(R_{\mathrm{a}}=1.25-1.35 \mu \mathrm{m}\right)$. During diamond grinding, splits and flaws occurred on the cutting edge of the sharpened tools due to the brittleness of diamond PSHM and to the significant mechanical and thermal stress fields developed; these defects reflected on quality of the components machined by these tools. On the contrary, during sharpening (i.e. finishing) of diamond PSHM cutters with R-EDM such splits were not formed leading to better finish of the turned components.

Summarizing the result of the tool life tests, it may be concluded that the proposed two-stage EDM, technological scheme is - at least - equally efficient for fabricating diamond PSHMs edge tools as compared with conventional diamond grinding.
Finally, the industrial applications of the proposed twostage EDM should be mentioned: Nowadays, diamond PSHM cutters fabricated according to this technique, are already used in various industrial sectors, for the precision machining of components from copper alloys ("Connector Ltd."/Kharkov/Ukraine), for turning of products from advanced plastics ("voloknit" in "Wings Ltd."/Cheboksary/ Russia), etc. As far as the economic potential of the proposed technique is concerned it should be noted that preliminary calculations indicated that the cost of diamond PSHM edged tools fabricated with the present "two-stage EDM" method, is reduced by 1.8-3 times as compared to existing grinding methods.

\section{Conclusions}

Summarizing the main features of the results reported above pertaining to the fabrication of cutting tools from diamond PSHMs it is concluded that the proposed "two-stage electro-discharge machining" is feasible and applicable. This technique employs first wire-electrode EDM for rough cutting and subsequently rotational disc-electrode EDM for finishing operations. Cutting tools with sufficient structural integrity and no defects were fabricated and their performance in turning was successfully tested. Overall, experimental results obtained clearly indicate the applicability of the proposed two-stage technique for fabricating precision cutting tools that can be used for the production of machined components made from glass and plastics, ceramics, composite materials and non-ferrous metals, at an industrial scale.

\section{References}

[1] H. Nakazawa, Principles of Precision Engineering, Oxford University Press, London, UK, 1994.

[2] A.G. Mamalis, C.G. Vosniakos, N.M. Vaxevanidis, X. Junzhe, Residual stress distribution and structural phenomena of high-strength steel surfaces, Ann. CIRP 37 (1) (1988) 531-535.

[3] W. Konig, D.F. Dauw, G. Levy, U. Panten, EDM-future steps towards the machining of ceramics, Ann. CIRP 37 (2) (1988) 623-631.

[4] T.C. Lee, W.S. Lau, Some characteristics of electrical discharge machining of conductive ceramics, Mater. Manufact. Process. 6 (4) (1991) 635-648.

[5] A.G. Mamalis, N.M. Vaxevanidis, D.I. Pantelis, On the electrodischarge machining of ceramic plasma-sprayed steel plates, Ann. CIRP 41 (1) (1992) 235-238.

[6] C.C. Wang, B. Haw Yan, Blind hole drilling of $\mathrm{Al}_{2} \mathrm{O}_{3}$ composite using rotary electro-discharge machining, Mater. Process. Technol. 102 (2000) 90-102.

[7] K. Steinmetz, A. Nimmich, P. Friedrich, Drahterosive Schneidkantenpraeparation von SYNDITE PKD, Industrie Diamanten Rundschau 3 (1990) 149.

[8] G. Spur, J. Schoenbeck, Funkenerosives Trennen polykristalliner Diamant-werkzeuge, Industrie Diamanten Rundschau 3 (1991) 179.

[9] G.G. Karyuk (Ed.), Technological Features of Machining by Means of Tools from Polycrystallic Superhard Materials, Naukova Dumka, Kiev, Ukraine, 1991 
[10] M.G. Magazeev, Raising the efficiency of making the profile tools made of superhard and ceramic materials on account of joint use electroerosion and diamond machining, PhD Thesis, State Polytechnical University Kharkov, Ukraine, 1997 (in Russian).

[11] J. Prohaszka, A.G. Mamalis, N.M. Vaxevanidis, The effect of electrode materials on machinability in wire electro-discharge machining, J. Mater. Process. Technol. 69 (1997) 233-237.
[12] Y.K. Lok, T.C. Lee, Processing of advanced ceramics using the wire-cut EDM process, J. Mater. Process. Technol. 63 (1997) 839843.

[13] P.S. Sreejith, B.K.A. Ngoi, New materials and their machining, J. Adv. Manufact. Technol. 18 (8) (2001) 537-544. 